\title{
Efficacy of tranexamic acid in preventing postpartum haemorrhage in vaginal delivery
}

\section{G. Anantha Lakshmi Satyavathi, Chandrika K.*}

\begin{abstract}
Department of Obstetrics and Gynecology, GSL Medical College and General Hospital, Rajahmundry, Andhra
\end{abstract} Pradesh, India

Received: 30 July 2019

Accepted: 07 August 2019

*Correspondence:

Dr. Chandrika K.,

E-mail: chandrikakanne@yahoo.co.in

Copyright: (c) the author(s), publisher and licensee Medip Academy. This is an open-access article distributed under the terms of the Creative Commons Attribution Non-Commercial License, which permits unrestricted non-commercial use, distribution, and reproduction in any medium, provided the original work is properly cited.

\begin{abstract}
Background: Postpartum blood loss is difficult to evaluate especially in developing countries like India where most of the women are anaemic with poor reserve and these conditions are further aggravated by increased demand during pregnancy and blood loss during third stage of labour. The present study was planned to compare the efficacy of prophylactic $10 \mathrm{IU}$ intramuscular oxytocin and $10 \mathrm{IU}$ intramuscular oxytocin $+1 \mathrm{~g}$ Tranexamic acid in reducing blood loss in the third stage of labour.

Methods: The present study was carried out on full term pregnancies primigravida/ multiparas with singleton pregnancy being delivered vaginally at GSL Hospital, Rajahmundry between 2016-2017 were included. For this comparative study, 200 women in labor were included after obtaining informed consent. A detailed obstetric history, history of previous medical illnesses, history of the treatment received earlier, cardiovascular and respiratory system and other systems including thyroid and breast were noted.

Results: The average total blood loss in IIIrd stage of labour with IM oxytocin was $210 \mathrm{ml}$ and with IM oxytocin + Tranexamic acid was $130 \mathrm{ml}$, which was statistically significant $(\mathrm{p}<0.001)$. Oxytocin + Tranexamic acid group had less blood loss when compared to oxytocin group alone. Side effects like, nausea vomiting, headache were slightly more with oxytocin + Tranexamic acid group when compared to oxytocin group alone.

Conclusions: In the active management of IIIrd stage of labour $10 \mathrm{IU}$ intramuscular Oxytocin + one gram of tranexamic acid IV is a better combination in reducing the blood loss at delivery when compared to 10 IU intramuscular oxytocin alone.
\end{abstract}

Keywords: Blood loose, Oxytocin, Postpartum haemorrhage, Third stage labour, Tranexamic acid, Vaginal delivery

\section{INTRODUCTION}

Postpartumhaemorrhage (PPH) is a major cause of maternal mortality, accounting for one quarter of all maternal deaths worldwide with an incidence from $3 \%$ to $15 \%$ of deliveries.

Postpartum blood loss is difficult to evaluate especially in developing countries like India where most of the women are anaemic with poor reserve and these conditions are further aggravated by increased demand during pregnancy and blood loss during third stage of labour.

Two thirds of postpartum haemorrhage occurs in women with no identifiable risk factors. Without proper management, $\mathrm{PPH}$ can rapidly progress to cause life threatening blood loss, often within few hours. Because 
of this unpredictability and rapid progression, for reducing the incidence of $\mathrm{PPH}$ and improving $\mathrm{PPH}$ outcome it does often remains a challenge, where maternal mortality is high and resources are limited. ${ }^{2}$ The introduction of low cost evidence based practices to prevent and manage PPH can improve maternal and infant survival. Routine practice of active management of third stage of labour (AMTSL) has been dramatically reduced haemorrhage by up to $60 \%$.

Active management of the third stage of labor is for the prevention of postpartum haemorrhage as per WHO guidelines. Postpartum haemorrhage (PPH) is classically defined as blood loss of $500 \mathrm{~mL}$ or more after vaginal delivery. With an incidence from $3 \%$ to $15 \%$ of deliveries, about one in five of these haemorrhages progresses to a severe form that may endanger the mother's life or at least her future fertility and exposes her to the risks of transfusion, surgery, and intensive care. PPH remains a leading cause of maternal mortality and accounts for about one quarter of all maternal deaths worldwide. Its risk factors include previous $\mathrm{PPH}$, primiparity, obesity, prolonged or Augmented labor, multiple pregnancy, previous cesarean delivery, polyhydramnios, and macrosomia. ${ }^{3,4}$

Active management of the third stage of labour (AMTSL) first described in the UK and in Ireland, consisted, as initially conceived, of a combination of the following interventions, preventive administration of uterotonic agents immediately after delivery of the child, early cord clamping and cutting, controlled cord traction (CCT) 5 and, according to some authors, uterine massage.

Administration of uterotonics6 and in particular oxytocin, after birth is the only component of AMTSL that is effective in preventing PPH. However, in addition to this enhancement of mechanical haemostasis, a complementary biochemical haemostatic effect might be expected from the complementary use of prohaemostatic drugs such as tranexamic acid.

Based on this framework the present study is aimed at comparing the efficacy of prophylactic 10 IU intramuscular oxytocin and 10 IU intramuscular oxytocin $+1 \mathrm{~g}$ Tranexamic acid in reducing blood loss in the third stage of labour.

Objective of this study were to determine efficacy and safety of tranexamic acid in preventing postpartum haemorrhage in vaginal delivery.

\section{METHODS}

The present study was carried out on full term pregnancies primigravida/ multipara (parity not more than two) with singleton pregnancy being delivered vaginally were included in the study at GSL Hospital, Rajahmundry between 2016-2017. For this comparative study, 200 women in labor were included after obtaining informed consent.

All of them had routine antenatal investigations including hemoglobin estimation, packed cell volume, blood grouping and typing, screening for blood sugar, VDRL, HbsAg, HIV with consent, urine routine, ultrasonography, repeat $\mathrm{Hb} \%$ and PCV on day two after delivery.

100 women were allotted to group-I (IM oxytocin) and 100 women to Group-II (IM oxytocin +Tranexamic acid). The data was collected in a specified proforma.

\section{Inclusion criteria}

- Primi gravida and multigravida with singleton pregnancy

- Planned vaginal delivery

- $\quad$ Term $\geq 37$ weeks of gestation.

\section{Exclusion criteria}

- Presence History of venous (deep vein thrombosis and/or pulmonary embolism) or arterial (angina pectoris myocardial infarction, stroke) thrombosis

- History of epilepsy or seizure

- Any known cardiovascular, renal, or liver disorders

- Autoimmune disease

- Sickle cell disease

- Severe hemorrhagic disease

- Placenta previa

- Abnormally invasive placenta (placenta accreta/increta/percreta) abruptio placenta

- Eclampsia

- HELLP syndrome

- Multiple pregnancy

- Intra uterine fetal death

- Allergic to tranexemic acid.

A detailed obstetric history, menstrual history, history of previous medical illnesses and history of the treatment received earlier. A detailed examination of cardiovascular and respiratory system and other systems including thyroid and breast was also noted.

The patients were continuously monitored and the delivery was conducted as per the guidelines.1gm Tranexamic acid IV slowly over 5 minutes + IM oxytocin and IM oxytocin were given after the delivery of the baby to the patients in respective groups.

The details of blood loss were measured following placental delivery to 2 hours after delivery. Vital data, uterine contractility, placental separation, side effects caused by tranexemic acid were noted.

Immediately after delivery of the baby, when all the liquor was drained, a plastic $\mathrm{v}$ brass drape was placed 
under the buttocks. Blood collected from measuring bag, soaked pads were weighed by electronic scale before and after the delivery.

The quantity of blood loss (ml) was estimated by the weight of the used materials in both the periods pre and post delivery were subtracted. Weight of the materials prior to the delivery, the blood loss measured in bag after placental delivery measured in $\mathrm{ml}$. The pads used after placental delivery to 2 hours postpartum were weighed, the amount of blood loss before baby delivery was thus not included in blood loss in the present study. Hemoglobin and hematocrit were noted before and on $2^{\text {nd }}$ day after delivery. Blood collected in bag and soaked pads were weighed by electronic scale before and after the delivery. This study was approved by ethical review committee of GSL Hospital Rajahmundry.

\section{Estimation of blood loss}

\section{Visual method}

Visual method of blood loss estimation is a quick, simple and noninvasive method. Blood loss estimation was done from the onset of third stage of labour to the end of stoppage of active bleeding. ${ }^{7}$

Fixed sized mops were $(10 \mathrm{x} 10 \mathrm{~cm})$ used in the present study for the estimation of blood loss. The soaking characteristics of the mops were used to estimate total blood loss. Depending on the soakage percentage the blood volume was calculated. Blood spillage on the delivery table, garments and floor were calculated/bag assessed. Total blood loss was calculated.

Hemoglobin/PCV measurement was done at the time of admission and, 48 hours postpartum and its correlation was done with blood loss.

\section{Gravimetric (measurement by weight) method}

It involves the weighing of collected blood lost during childbirth along with materials such as all contaminated linens, pads, towels, or swabs on a sensitive scale and then deducting the known dry weights of these materials to find out the actual amount of blood loss. The difference in weight was the actual loss in $\mathrm{ml}$. However, other types of fluid, such as amniotic fluid or urine that are present at the time of delivery cannot be avoided or discriminated from the blood during the process of weighing. ${ }^{7,8}$

\section{Photometry}

A photometric technique (also known as the alkaline haematin method) involves the conversion of blood pigment to alkaline haematin. This technique is considered as the gold standard for measuring blood; photometric methods are considered the most accurate technique for estimation of blood loss, the procedure poses several limitations.

For research purpose, it can be recommended that combining two methods would be ideal to reduce errors and increase accuracy when measuring postpartum blood loss. Combining the gravimetric method along with direct blood measurement can be proposed as appropriate blood loss estimation technique. This would be a cheap method and increase the accuracy of blood loss estimation.

\section{Estimation of blood loss after the delivery of placenta}

Estimation of the blood loss in the third stage is grossly inaccurate when this is done by inspection alone. Gatch and little compared photometric estimation of acid hematin, prepared by diluting the patient's venous blood before and after delivery. ${ }^{9}$ Coller et al, compared pre and post delivery hemoglobin and plasma protein concentrations. ${ }^{10}$ Murdoch attempted complete collection in calibrated receptacles. ${ }^{11}$ Brandt used a washing machine method to measure the blood loss. ${ }^{12}$ A more accurate method of determining the effects of blood loss and the amount to be replaced involves the measurement of central venous pressure ( $\mathrm{O}^{\prime}$ Driscoll and McCathy). ${ }^{13}$

\section{Statistical analysis}

All the statistical analysis was done by using spss 20.0 software version and MS excel-2007. Descriptive data was presented as mean \pm standard deviation and percentages. t-test was done to compare the means of different groups. Chi-square test was done to assess the associates among different categorical variables. $\mathrm{P}<0.05$ was considered as statistically significant.

\section{RESULTS}

The majority of patients in both the groups was aged between 21-26 years and had their BMI between 24$25 \mathrm{~kg} / \mathrm{m}^{2}$.

Table 1: Comparison of vital parameters between groups.

\begin{tabular}{|lccc|}
\hline $\begin{array}{l}\text { Parameters } \\
\text { Pulse rate }\end{array}$ & $\begin{array}{c}\text { Pre- } \\
\text { delivery }\end{array}$ & $\begin{array}{l}\text { Post- } \\
\text { delivery }\end{array}$ & p-value \\
\hline Study group & 85.4 & 85.4 & $\mathrm{p}>0.05$ \\
\hline Control group & 85.76 & 88.6 & $\mathrm{P}<0.01$ \\
\hline SBP & & & \\
\hline Study group & 110.9 & 110.9 & $\mathrm{p}>0.05$ \\
\hline Control group & 110.8 & 108.2 & $\mathrm{P}<0.01$ \\
\hline DBP & & & \\
\hline Study group & 76.9 & 76.9 & $\mathrm{p}>0.05$ \\
\hline Control group & 76.8 & 74.2 & $\mathrm{P}<0.01$ \\
\hline Haemoglobin (gm\%) & & \\
\hline Study group & 10.4 & 10.4 & \\
\hline Control group & 10.4 & 10.2 & \\
\hline
\end{tabular}


Forty seven patients in study group and forty six patients in control group were primigravida.

Fifty three patients in study group and fifty four patients in control group were second gravida.

The blood loss at the end of two hours was $130 \mathrm{ml}$ in study group and $210 \mathrm{ml}$ in control group. The blood loss was significantly low in the study group compared to the control group

The mean increase in pulse rate of $2.84 \mathrm{bpm}$ in control group after post delivery $(\mathrm{p}<0.01)$, there is no difference in pre and post delivery pulse rate in study group $(\mathrm{p}>0.05)$.

The mean fall in systolic Bp in control group is $2.6 \mathrm{mmHg}$ and mean fall in diastolic $\mathrm{Bp}$ is $2.6 \mathrm{mmHg}$ in control group. There is no fall in systolic and diastolic Bp in study group $(p>0.05)$. There is a statistically significant increase in the pulse rate and decrease in blood pressure in the control group as compared with the study group (Table 1).

Table 2: Complications between groups.

\begin{tabular}{|ll|ll|}
\hline & $\begin{array}{l}\text { Study } \\
\text { group }\end{array}$ & $\begin{array}{l}\text { Control } \\
\text { group }\end{array}$ & $\begin{array}{l}\mathrm{p} \text { - } \\
\text { value }\end{array}$ \\
\hline Vomiting and Headache & 2 & 5 & 0.2 \\
\hline Need for blood transfusion & 0 & 2 & 0.1 \\
\hline Additional uterotonics used & 0 & 3 & 0.08 \\
\hline Third stage complications & 0 & 1 & 0.8 \\
\hline
\end{tabular}

In this study $5 \%$ of women had vomitings and headache in oxytocin group. $2 \%$ of women in the TXA and oxytocin group p-value was 0.1 which was statistically not significant.

In this study $2 \%$ of women needed blood transfusion in oxytocin group. No women in the oxytocin and tranexamic acid group needed blood transfusion and the p-value was 0.1 which was statistically not significant. $3 \%$ of women in the control group needed additional oxytocin and carboprost, which was statistically insignificant $(\mathrm{p}=0.08)$.

There was no third stage complication in study group, only one patient had PPH in control group. The patients in control group who had postpartum blood loss, lost almost $450-500 \mathrm{ml}$ of blood. There was no incidence of retained placenta or third stage complications in the both groups (Table 2).

In both groups placenta was expelled completely within 5-6 minutes, $98 \%$ cases in control and $100 \%$ in study group. The duration of third stage of labour was more than $6 \mathrm{~min}$ in control group, which was statistically insignificant $(\mathrm{p}=0.89)$. There was no incidence of retained placenta in this study.
Table 3: Duration of third stage of labour and hospital stay between groups.

\begin{tabular}{|c|c|c|c|}
\hline & Study group & Control group & p-value \\
\hline \multicolumn{3}{|c|}{$\begin{array}{l}\text { Duration of third stage of labour } \\
\text { (minutes) }\end{array}$} & \multirow{6}{*}{0.89} \\
\hline 4 & 9 & 8 & \\
\hline 5 & 53 & 52 & \\
\hline 6 & 35 & 36 & \\
\hline 7 & 3 & 3 & \\
\hline 8 & 0 & 1 & \\
\hline \multicolumn{3}{|c|}{ Duration of hospital stay (days) } & \multirow{3}{*}{0.08} \\
\hline$<3$ & 100 & 97 & \\
\hline$>3$ & 0 & 3 & \\
\hline
\end{tabular}

Duration of hospital stay was $3 \%$ in group I for $>3$ days stay where as $100 \%$ for group-II in <3 days stay which was statistically insignificant (0.08) (Table 3$)$.

\section{DISCUSSION}

In the present study, most common age group is between 21-25 years. Majority of the patients in the two groups were between 18-25 years. Very few patients were in the age group between 26-30 years. Age difference in the two groups was not significant $(\mathrm{p}=0.1)$.

In the study conducted by Roy $\mathrm{P}$ et al, the median maternal age was 23.75 range (20-30) years. There was no statistical significance in the age group. ${ }^{14}$ Ferrer $\mathrm{P}$ et al in their study done on 300 women with median age of 23.50 years there was no statistical significance in the both groups. ${ }^{15}$ Yang et al in their study on 400 women the median age of 22.75 years there was no statistical difference between the two groups. ${ }^{16}$ Gungorkuk et al, in their study on 450 women with the median age of 22.50 years there was no statistical difference between the two groups. ${ }^{17}$

In the present study primi gravida were $47 \%$ and $46 \%$ in oxytocin group Multigravida $53 \%$ and $54 \%$ in oxytocin group respectively. There was no statistical significance $(\mathrm{p}=0.88)$. Roy $\mathrm{P}$ et al in their study primigravida were $10 \%$ and $15 \%$ in oxytocin group. Multigravida are $40 \%$ in study group and $35 \%$ in control group there was no statistical difference between the two groups. ${ }^{14}$

The duration of third stage of labour is more than 6 minutes in oxytocin group. There was no influence of the drug in the duration of third stage of labour only $3 \%$ of cases in the control group needed uterotonics were two patients needed Inj. carboprost and inj. Methergine $0.2 \mathrm{mg}$ and $2 \%$ of patients needed blood transfusion in oxytocin group compared to Tranxemic acid and oxytocin group $(p=0.8)$. The patients in control group who had postpartum blood loss, lost almost $450-500 \mathrm{ml}$ of blood. There was no incidence of retained placenta or third stage complications in the both groups. 
In Roy $\mathrm{P}$ et al, in his study the mean duration of third stage of labour was $4.6 \mathrm{~min}$ in the study group and $4.48 \mathrm{~min}$ in the control group. $22 \%$ of the patients in the control group needed additional uterotonics compared to only $2 \%$ in the study group. There was a significant difference in the requirement of uterotonics between the two groups. $10 \%$ of the patients in the oxytocin group needed blood transfusion compared to $2 \%$ in the study group. There was a significant difference in the need for blood transfusion between the two groups. The patients in the both groups who had postpartum haemorrhage had 400-500ml blood loss. ${ }^{14}$

In the present study the average total blood loss with oxytocin is 210.15 and with Tranxemic acid and oxytocin is $131 \mathrm{ml}$. The mean difference in the blood loss was statistically significant $(\mathrm{p}<0.05)$. The blood loss was significantly low in the study group compared to the control group.

In the present study the duration of Hospital stay was $>3$ days in oxytocin group which was 3\% compared to Tranxemic acid group were $100 \%$ are discharged with in $<3$ days $(\mathrm{p}=0.08)$

In Roy's P study the average total blood loss at the end of two hours was $105 \mathrm{ml}$ in the study group and $250 \mathrm{ml}$ in the control group. The blood loss was significantly low in the study group compared to the control group. In his study there was no significant difference in maternal complications such as vomiting, diarrhoea, headache or fever between the two groups. In his study $12 \%$ of the patients in the control group had to stay for more than 3 days compared to $2 \%$ in the study group. ${ }^{14}$

In the present study $2 \%$ of women in Tranxemic acid and oxytocin group had vomiting and headache, compared to $5 \%$ of oxytocin group and which was statistically not significant $(\mathrm{p}=0.24)$.

Majority of patients in both groups were having pre delivery haemoglobin in the range of 10.1-11gms with a mean of 10.4 in $100 \%$ in both groups and which was statistically insignificant $(\mathrm{p}=0.99)$. The postdelivery haemoglobin in the range of 10.4 in study group and 10.2 in control group $(\mathrm{p}=0.08)$.

In the present study, pre-delivery systolic and diastolic blood pressure are same, after delivery there is a minimal fall in systolic and diastolic blood pressure and increased pulse rate in oxytocin group compared to study group as there is $3 \%$ cases needed blood transfusion, which is statistically significant.

In Roy's P study the mean increase in pulse rate was 1.40 $\mathrm{bpm}$ in study group and $5.60 \mathrm{bpm}$ in control group, the mean fall in systolic BP was $1.40 \mathrm{mmHg}$ in the study group and $3.30 \mathrm{mmHg}$ in control group. Mean fall in diastolic BP was $0.50 \mathrm{mmHg}$ in study group and $3.20 \mathrm{mmHg}$ in control group. There was a statistically significant increase in the pulse rate and decrease in blood pressure in the control group as compared to study group. $^{14}$

The mean fall in haemoglobin was $0.20 \mathrm{gm} \%$ in study group and $0.70 \mathrm{gm} \%$ in control group. Mean fall in haematocrit was $0.40 \%$ in study group and $1.20 \%$ in control group. The postdelivery haemoglobin and haematocrit were significantly reduced in the control group as compared to the study group. This study showed that tranexamic acid significantly reduces bleeding from time of placental delivery to 2 hours post partum in vaginal delivery. This study shows significant decrease in the incidence of blood loss in the study group as compared to control group ( $p$ value <0.05). Similar findings were also reported by Priyankur Roy, $\mathrm{Z}$ heng et al showed similar results in vaginal delivery. ${ }^{14,15}$

This study was a prospective randomized controlled type which showed that TXA significantly reduced bleeding from the time of placental delivery to two hours postpartum in vaginal delivery. This study shows significant decrease in the bleeding volume in TXA group as compared with the placebo group. Roy's P showed similar comparable results reducing the blood loss in the study group.

Yang et al, reported, the measurement of blood loss two hours after delivery $243 \mathrm{ml}$ in study and $314 \mathrm{ml}$ in control group with a $p$ value $<0.01$ without any side effects. ${ }^{16}$

Gungorkuk et al reported, mean blood loss during the $3^{\text {rd }}$ and $4^{\text {th }}$ stage of labour, from the end of delivery to 2 hours postpartum the method of measurement of blood loss taken are weight of material used - weight of materials before use. The mean loss in study group $260 \mathrm{ml}$ and $350 \mathrm{ml}$ in control group with a $\mathrm{p}$ value $<0.001$ with mild gastrointestinal side effects and no thromboembolic events. ${ }^{17}$

Gai et al, showed, mean blood loss was $360 \mathrm{ml}$ in study group and $440 \mathrm{ml}$ in control group, with a $\mathrm{p}$ value of 0.002 with no side effects. ${ }^{18}$

Gohel et al, showed mean blood loss was $375 \mathrm{ml}$ in study group and $470 \mathrm{ml}$ in control group the $\mathrm{p}$ value 0.003 with no thromboembolic or other side effects. ${ }^{19}$

Gulmezogulu AM et al, reported, mean blood loss was $240 \mathrm{ml}$ in study group and $500 \mathrm{ml}$ in control group $(\mathrm{p}<0.001) .^{20}$

Therefore the use of TXA appears to reduce the blood loss, severe anemia following postpartum bleeding is an important cause of maternal morbidity and is likely to make more women more vulnerable to fatal postpartum haemorrhage in future pregnancies.

Reducing blood loss would also reduce the risks and costs associated with blood transfusion. The use of TXA 
will decrease the risk of transfusion-transmitted viral infections because fewer units of blood will be transfused.

There was no significant alteration in the vital signs of subjects following tranexamic acid administration. There was no abnormalities in hemoglobin, liver and renal function and urine analysis. The incidence of thrombosis during pregnancy and puerperium is 5-6 times higher than that in the general population. When the antifibrinolytic drug, tranexamic acid is administered, the increased rate of postpartum thrombosis after vaginal delivery should be considered.

In the present study, not a single patient developed thrombosis and incidence of side effects like nausea, vomiting and diarrhoea were not statistically significant by difference in the two groups.

Administration of TXA in pregnant women may raise concerns about thromboembolism, however previous studies have shown the safety of this drug for use in both pregnant and non pregnant patients. Side effects like nausea, vomiting and diarrhea were not statistically significant by differences in the two groups.

\section{CONCLUSION}

In the active management of III $^{\text {rd }}$ stage of labour $10 \mathrm{IU}$ intramuscular Oxytocin + one gram of tranexamic acid IV is a better combination in reducing the blood loss at delivery when compared to 10 IU intramuscular oxytocin alone. As the advantages are more and the side effects are very minimal with this combination, more studies with this combination are required in the more common vaginal deliveries also to save the mother's from blood loss.

Funding: No funding sources

Conflict of interest: None declared

Ethical approval: The study was approved by the Institutional Ethics Committee

\section{REFERENCES}

1. Smith JR, Brennan BG. Postpartum hemorrhage. E Medicine. 2006;13:1-9.

2. Pattinson RC. Overview-third report on confidential enquiries into maternal deaths in South Africa 20022004: overview. In Obstetrics Gynaecology Forum 2006;16(3):79-82.

3. Ferrazzani S, Guariglia L, Draisci G, Sorrentino L, De Stefano V, D'Onofrio G, et al. Postpartum hemorrhage. Minerva Gynecol. 2005;57(2):111-29.

4. Obstet IJ. Diagnosis and management of postpartum hemorrhage. Int J Gynecol Obstet. 1991;36:159-63.

5. Deneux-Tharaux C, Sentilhes L, Maillard F, Closset E, Vardon D, Lepercq J, et al. Effect of routine controlled cord traction as part of the active management of the third stage of labour on postpartum haemorrhage: multicentre randomised controlled trial (TRACOR). BMJ. 2013;346:f1541.

6. Soltani H, Hutchon DR, Poulose TA. Timing of prophylactic uterotonics for the third stage of labour after vaginal birth. Cochrane Database of Systematic Reviews. 2010(8).

7. Meiser A, Casagranda o, Skipka G, Laubenthal M. quantification of blood loss. How precise is visual estimation and what does its accuracy depend on? Anaesthetist. 2001;50:13-20.

8. Didly GA, paine AR, George NC, Velasco C. Estimating blood loss: can teaching significantly improve visual estimation? Obstet Gynecol. 2004;104:601-6.

9. Gatch WD, Little WD. Amount of blood lost during some of the more common operations: preliminary report. J Am Med Assoc. 1924;83(14):1075-6.

10. Coller FA, Campbell KN, Vaughan HH, Iob LV, Moyer CA. Postoperative salt intolerance. Ann Surg. 1944;119(4):533.

11. Murdoch JM, Campbell GD. Antithyroid Activity of N-Phthalyl Glutamic Acid Imide (K17). Br Med J. 1958;1(5062):84.

12. Brant HA. Blood loss at caesarean section. BJOG: Int J Obstet Gynaecol. 1966;73(3):456-9.

13. O'Driscoll K, McCarthy JR. Abruptio placentae and central venous pressures. BJOG. 1966;73(6):923-9.

14. Roy P, Sujatha MS, Bhandiwad A, Biswas B, Chatterjee A. Placental blood drainage as a part of active management of third stage of labour after spontaneous vaginal delivery. J Obstet Gynecol India. 2016;66(1):242-5.

15. Ferrer P, Roberts I, Sydenham E, Blackhall K, Shakur H. Anti-fibrinolytic agents in post partum haemorrhage: a systematic review. BMC pregnancy and childbirth. 2009;9(1):29.

16. Yang $\mathrm{H}$, Zheng $\mathrm{S}$, Shi C. Clinical study on the efficiency of tranexamic acid in reducing postpartum blood loss - a randomized multicentre trial. Zhonghua Fu Chan Zazhi. 2001;36(10):590-2.

17. Gungorduk K, Yildirim G, Ascioglu O, Gungorduk OC, Sudolmus S, Ark C. Efficacy of intravenous tranexamic acid in reducing blood loss after elective caesarean section: a prospective, randomized, double blind, placebo controlled study. Am J Perinatol. 2011;28:233-40.

18. Gai MY, Wu LF, Su QF. Clinical observation of blood loss reduced by tranexamic acid during and after caesarean section: a multicentre randomized trial. Eur J Obste Gynaecol Reprod Biol. 2004;112(2):154-7.

19. Gohel M, Patel P, Gupta A, Desai P. Efficacy of tranexamic acid in decreasing blood loss during and after caesarean section: a randomized case controlled prospective study. J Obstet Gynaecol India. 2007;57:227-30.

20. Gulmezogulu AM, Lumbiganon P, Landousi S, Widmer M, Abdel-Aleem H, Festin M, et al. Active management of the third stage of labour with and without controlled cord traction: a randomized, 
controlled, non-inferiority trial. Lancet. 2012;379:1721-7.

Cite this article as: Satyavathi GAL, Chandrika K. Efficacy of tranexamic acid in preventing postpartum haemorrhage in vaginal delivery. Int J Reprod Contracept Obstet Gynecol 2019;8:3485-91. 